\title{
SoxV transfers electrons to the periplasm of Paracoccus pantotrophus - an essential reaction for chemotrophic sulfur oxidation
}

Correspondence
Cornelius G. Friedrich
cornelius.friedrich@udo.edu

Received 14 September 2005

Revised 7 November 2005

Accepted 7 November 2005

\author{
Frank Bardischewsky, Jörg Fischer, Bettina Höller \\ and Cornelius G. Friedrich \\ Lehrstuhl für Technische Mikrobiologie, Fachbereich Bio- und Chemieingenieurwesen, \\ Universität Dortmund, D-44221 Dortmund, Germany
}

\begin{abstract}
The soxVW genes are located upstream of the sox gene cluster encoding the sulfur-oxidizing ability of Paracoccus pantotrophus. SoxV is highly homologous to CcdA, which is involved in cytochrome $c$ maturation of $P$. pantotrophus. SoxV was shown to function in reduction of the periplasmic SoxW, which shows a CysXaaXaaCys motif characteristic for thioredoxins. From strain $\mathrm{GB} \Omega \mathrm{V}$, which carries an $\Omega$-kanamycin-resistance-encoding interposon in sox $V$, and complementation analysis it was evident that SoxV but not the periplasmic SoxW was essential for lithoautotrophic growth of $P$. pantotrophus with thiosulfate. However, the thiosulfate-oxidizing activities of cell extracts from the wild-type and from strain $\mathrm{GB} \Omega \mathrm{V}$ were similar, demonstrating that the low thiosulfate-oxidizing activity of strain $\mathrm{GB} \Omega \mathrm{V}$ in vivo was not due to a defect in biosynthesis or maturation of proteins of the Sox system and suggesting that SoxV is part of a regulatory or catalytic system of the Sox system. Analysis of DNA sequences available from different organisms harbouring a Sox system revealed that soxVW genes are exclusively present in sox operons harbouring the sox $C D$ genes, encoding sulfur dehydrogenase, suggesting that SoxCD might be a redox partner of SoxV. No complementation of the $\operatorname{ccd} A$ mutant $P$. pantotrophus TP43 defective in cytochrome $c$ maturation was achieved by expression of soxV in trans, demonstrating that the high identity of SoxV and CcdA does not correspond to functional homology.
\end{abstract}

\section{INTRODUCTION}

The reversible formation of protein-disulfide bonds plays an important role in transport of electrons, protein biogenesis, protein stability and enzyme catalysis (Akyama \& Ito, 1993; Yamanaka et al., 1994; Okamoto et al., 1995; Missiakis \& Raina, 1997; reviewed by Fabianek et al., 2000; Ritz \& Beckwith, 2001). Different thiol: disulfide oxidoreductases have been identified which are involved in the formation, isomerization and reduction of disulfide bonds in different bacteria. All these oxidoreductases share a conserved CysXaaXaaCys motif and a common tertiary structure known as the thioredoxin-like fold (Martin, 1995). Members of the DsbD and CcdA families are involved in the transport of electrons from the cytoplasm to the periplasm for reduction of apocytochromes to enable addition of the haem moiety (reviewed by Thöny-Meyer, 1997). The electrons are transferred from a cytoplasmic thioredoxin first to the central transmembrane $\beta$-domain of DsbD then to the Cterminal thioredoxin-like $\gamma$-domain and therefrom to the $\mathrm{N}$-terminal $\alpha$-domain, which then reduces either DsbC or

Abbreviations: AMS, 4-acetamido-4'-maleimidylstilbene-2,2'-disulfonic acid; Sox, sulfur oxidation; TCEP, tris(2-carboxyethyl)phosphine; TMPD, $N, N, N^{\prime}, N^{\prime}$-tetramethyl-1,4-benzenediamine.
CcmG (Rietsch et al., 1997; Stewart et al., 1999; Chung et al., 2000; Katzen \& Beckwith, 2000).

The Gram-negative, facultatively chemolithoautotrophic bacterium Paracoccus pantotrophus grows under aerobic conditions lithotrophically with molecular hydrogen and thiosulfate as energy source for autotrophic carbon dioxide fixation (Robertson \& Kuenen, 1983; Rainey et al., 1999). In $P$. pantotrophus the soxVWXYZABCDEFGH genes constitute two transcriptional units, soxVW and soxX-H (Rother et al., 2005). In the homogenote mutant $\mathrm{GB} \Omega \mathrm{V}$ carrying the $\operatorname{sox} V:: \Omega$-kanamycin interposon sox $X-H$ are expressed upon growth with thiosulfate as in the wild-type GB17 (Bardischewsky \& Friedrich, 2001b).

SoxV predicts a protein with six transmembrane helices which is closely related with respect to its primary and secondary structure to CcdA of $P$. pantotrophus and other bacteria involved in cytochrome $c$ biogenesis (Bardischewsky \& Friedrich, 2001a). SoxW predicts a periplasmic protein with characteristics of members of the thioredoxin superfamily (Bardischewsky \& Friedrich, 2001b). SoxV and CcdA of $P$. pantotrophus are $42 \%$ identical. Despite the high degree of identity the two proteins display completely different functions. Inactivation of $c c d A$ of $P$. pantotrophus causes 
pleiotropic effects due to the inability to mature $c$-type cytochromes which are involved in different metabolic pathways such as dissimilatory nitrite reduction, and hydrogen and thiosulfate oxidation. Therefore, for CcdA of $P$. pantotrophus a similar role was suggested as shown for DsbD of Escherichia coli (Crooke \& Cole, 1995; Bardischewsky \& Friedrich, 2001a) and CcdA of Bacillus subtilis (Schiött et al., 1997), which transport reductant from the cytoplasm into the periplasm, for re-reduction of the cytochrome $c$ apoprotein, an essential step for binding of the haem moiety.

Disruption of soxV of $P$. pantotrophus using the $\Omega-\mathrm{Km}$ interposon does not affect the cytochrome $c$ biogenesis or autotrophic carbon dioxide fixation (Bardischewsky \& Friedrich. 2001b). However, strain GB $\Omega$ V is unable to grow lithotrophically with thiosulfate. Thus, the function of SoxV differs from that of CcdA.

In this study we analysed the $\operatorname{sox} V:: \Omega-\mathrm{Km}$ disruption with respect to the activity of the thiosulfate-oxidizing system in vivo and in vitro. Whole cells of strain $\mathrm{GB} \Omega \mathrm{V}$ oxidized thiosulfate at a rate of about $2 \%$ as compared to the wildtype, whereas the rates of thiosulfate oxidation of cell extracts of strain GB $\Omega \mathrm{V}$ and of the wild-type were similar. We have identified SoxW to be maintained in the reduced state by SoxV. These results and complementation analysis suggest that SoxV transfers electrons via SoxW or another thioredoxin to an as yet unknown periplasmic target involved in thiosulfate oxidation in vivo and that SoxW is not essential and possibly substituted by other thioredoxins.

\section{METHODS}

Bacterial strains and plasmids. The E. coli strains used were S17-1 (recA pro thi hsdS, RP4 tra-functions supE44) (Simon et al., 1983) and

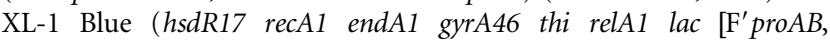
lacl ${ }^{\mathrm{q}} \mathrm{Z} \Delta \mathrm{M} 15 \operatorname{Tn} 10\left(\mathrm{Tet}^{\mathrm{r}}\right)$ ]) (Bullock et al., 1987; Stratagene). Paracoccus pantotrophus strains used were GB17 $\left(\mathrm{Sox}^{+} \mathrm{Hox}^{+}\right.$) (Robertson \& Kuenen, 1983; Rainey et al., 1999), GB $\Omega$ V (Sox ${ }^{-} \mathrm{Hox}^{\mathrm{L}}, \Omega-\mathrm{Km}$ interposon integrated in soxV) (Bardischewsky \& Friedrich, 2001b), GB $\Omega \mathrm{X}$ (Sox ${ }^{-}, \Omega-\mathrm{Km}$ interposon integrated in soxX) (Bardischewsky et al., 2005) and TP43 (Sox ${ }^{-}$cyt $c^{-}$, Tn5-mob integrated in $c c d A$ ) (Chandra \& Friedrich, 1986; Bardischewsky \& Friedrich, 2001a). Plasmid pBHP6 carrying the soxVW genes (Bardischewsky \& Friedrich, 2001b), pRIN2.6 the soxW gene, and pRIPVphoA the soxV gene (this study) were used for complementation studies. Plasmid pRIN2.6 was constructed from the $2 \cdot 6 \mathrm{~kb} \mathrm{NruI}$ fragment of pBSP3.4 (Bardischewsky \& Friedrich, 2001b) containing sox $V^{\prime} W X Y Z A^{\prime}$. The gene region was cloned into pJOE733.2 (Ap ${ }^{\mathrm{r}}$, lacZ $\alpha$ ) (Altenbuchner et al., 1992), resulting in pJOEN2.6. The $2.6 \mathrm{~kb}$ DNA fragment containing sox genes was isolated from pJOEN2.6 after PstI restriction, and it was then cloned into the PstI site of pRI1 $\left(\mathrm{Sm}^{\mathrm{r}} \mathrm{Cm}^{\mathrm{r}} \mathrm{Mob}^{+}\right.$) (Pfitzner et al., 1998) resulting in pRIN2.6. Construction of plasmid pRIPV phoA was done in two steps. First, the phoA gene was isolated from pPHO7 (Gutierrez \& Devedijian, 1989) by restriction with BamHI and XbaI, and cloned into pRI1, resulting in pRIphoA. Then the soxV region was amplified by PCR using primers PV1 (5'-CGGGATCCCGGGCCTGG-

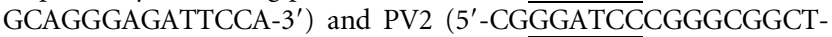
GCGGGTGCTGCCG-3'), which both introduced a restriction site for BamHI (underlined). Plasmid pBSP3.4 (Bardischewsky \& Friedrich, 2001b) was used as template. The $940 \mathrm{bp}$ amplified DNA fragment containing the $\operatorname{sox} \mathrm{V}$ gene region was restricted with $B a m \mathrm{HI}$ and cloned into the BamHI restriction site of pRIphoA, resulting in pRIPVphoA.

Media and growth conditions. Strains were cultivated at $30^{\circ} \mathrm{C}$. Mineral media were identical for heterotrophic, for mixotrophic and for lithotrophic growth of P. pantotrophus, and were described previously (Chandra \& Friedrich, 1986). For lithotrophic growth with thiosulfate, mineral media contained $20 \mathrm{mM}$ sodium thiosulfate at a final $\mathrm{pH}$ of $8 \cdot 0$. For mixotrophic growth, mineral media contained $20 \mathrm{mM}$ sodium succinate and $20 \mathrm{mM}$ sodium thiosulfate at a final $\mathrm{pH}$ of $7 \cdot 2$. E. coli was cultivated in Luria-Bertani medium (Sambrook et al., 1989). The following antibiotics were used when appropriate: for $P$. pantotrophus, $300 \mu \mathrm{g}$ kanamycin $(\mathrm{Km}) \mathrm{ml}^{-1}$ and $10 \mu \mathrm{g}$ chloramphenicol $(\mathrm{Cm}) \mathrm{ml}^{-1}$; for E. coli, $30 \mu \mathrm{g} \mathrm{Cm} \mathrm{ml} \mathrm{m}^{-1}, 100 \mu \mathrm{g}$ ampicillin (Ap) $\mathrm{ml}^{-1}$ and $12 \cdot 5 \mu \mathrm{g}$ tetracycline $(\mathrm{Tc}) \mathrm{ml}^{-1}$.

DNA techniques. Standard DNA techniques (Sambrook et al., 1989) were used. Plasmid DNA was isolated according to the procedure of Birnboim \& Doly (1979). Restriction enzymes, T4 DNA ligase and Klenow polymerase were obtained from Gibco-BRL and used as recommended by the manufacturer. DNA fragments were eluted from agarose gels using the QIAquick gel extraction kit (Qiagen).

Preparation of cell fractions. The A65 fraction and the membrane fraction were prepared from cells disrupted with a French press (Quentmeier et al., 2000). The extract was subjected to differential centrifugation at $4{ }^{\circ} \mathrm{C}$. Whole cells and cell debris were separated at $10000 \mathrm{~g}$ for $20 \mathrm{~min}$. The resulting cell-free extract was subjected to centrifugation at $200000 \mathrm{~g}$ for $2 \mathrm{~h}$ to separate the soluble periplasmic and cytoplasmic proteins from the membranes. Proteins of the supernatant were precipitated at $65 \%$ saturation ammonium sulfate as described by Quentmeier et al. (2000) and designated the A65 fraction. The $200000 \boldsymbol{g}$ pellet was washed twice with $50 \mathrm{mM}$ sodium phosphate buffer, $\mathrm{pH} 7 \cdot 4$, and designated the membrane fraction.

Periplasmic proteins were specifically extracted from the cells by osmotic shock according to the protocol of Qiagen (The QIAexpressionizt, protocol 4, 2nd edition). Tris/HCl pH 6.5 was added to the extract to give a final concentration of $25 \mathrm{mM}$.

Enzyme assays. Enzyme activities were determined from whole cells and cell-free extracts. The thiosulfate-dependent oxygen uptake rate of whole cells was determined using a polarographic oxygen electrode (Rank Brothers) as described by Wodara et al. (1997). The thiosulfate-dependent oxygen uptake rate of cell-free extracts was determined with the oxygen electrode similarly as for whole cells. The assay $(3.0 \mathrm{ml})$ contained $10 \mathrm{mg}$ protein of the membrane fraction and $30 \mathrm{mg}$ protein of the A65 fraction. Thiosulfate-dependent cytochrome $c$ reducing activity of the A65 fraction and of periplasmic extracts was determined spectrophotometrically at $550 \mathrm{~nm}$ as described by Quentmeier et al. (2000). One unit (U) of enzyme activity was defined as $1 \mu \mathrm{mol}$ cytochrome $c$ reduced or $\mathrm{O}_{2}$ utilized per minute at $30^{\circ} \mathrm{C}$. Whole cells were screened for cytochrome $c$ oxidase by verifying their capability to oxidize $N, N, N^{\prime}, N^{\prime}$-tetramethyl-1,4benzenediamine (TMPD). TMPD oxidation was monitored spectrophotometrically at $611 \mathrm{~nm}$. The assay $(1.0 \mathrm{ml})$ contained phosphate buffer $(36 \mathrm{mM}, \mathrm{pH} 8 \cdot 0), 50 \mu \mathrm{g}$ (dry weight) of whole cells and 2 mM TMPD.

Analytical procedures. SoxW was detected in cell-free extracts of $P$. pantotrophus strains by immunoblot analysis using a semidry procedure (Towbin et al., 1979). Antibodies against the immunogenic oligopeptide DDGLHKPTWLRETFK as deduced from the soxW nucleotide sequence were raised in rabbits at the facilities of Eurogentec (Seraing, Belgium). Ribulose-bisphosphate carboxylase 
(RubisCO) is a cytoplasmic enzyme and was used as marker protein to indicate the purity of the periplasmic extracts. Antibodies against RubisCO of Ralstonia eutropha, which were also active against the enzyme of $P$. pantotrophus (Bowien et al., 1976), were obtained from B. Bowien, Göttingen, Germany.

Thiosulfate was quantified according to Sørbø (1957).

Protein from cell-free extracts was quantified according to Bradford (1976).

Determination of the redox states of SoxW. The redox states of SoxW in vivo were determined by electrophoretic mobility after linking free thiols of proteins with 4 -acetamido-4'-maleimidylstilbene2,2'-disulfonic acid (AMS) according to Kobayashi et al. (1997) and by immunochemical identification of SoxW. Proteins of whole cells were precipitated by addition of trichloroacetic acid to the culture to a final concentration of $5 \%(\mathrm{w} / \mathrm{v})$. The precipitate was collected by centrifugation and washed twice with acetone. The pellet was dissolved in freshly prepared $50 \mathrm{mM}$ Tris/ $\mathrm{HCl}$ buffer, $\mathrm{pH} 7 \cdot 5$, containing $15 \mathrm{mM}$ AMS and $1 \%$ SDS. Reduced SoxW was prepared by incubation of periplasmic extract with $10 \mathrm{mM}$ tris(2-carboxyethyl)phosphine (TCEP) for $20 \mathrm{~min}$ at $30^{\circ} \mathrm{C}$. Proteins were then precipitated with trichloroacetic acid and washed twice with acetone as described above to remove TCEP. The precipitate was resuspended in freshly prepared $50 \mathrm{mM}$ Tris/ $\mathrm{HCl}$ buffer, $\mathrm{pH} 7 \cdot 5$, containing $1 \%$ SDS and $15 \mathrm{mM}$ AMS. Proteins were separated by SDS-PAGE in the absence of reductants. SoxW was detected by immunoblot analysis as described above.

Sequence analysis. Multiple alignments of amino acid sequences were performed using ClustalView (Thompson et al., 1994). The PHYLIP package (Felsenstein, 1989) was used to determine the phylogenetic relationships of CcdA and ShxV. The treefile was viewed using TreeView (Page, 1996).

\section{RESULTS}

\section{Complementation analysis of strain $\mathrm{GB} \Omega \mathrm{V}$}

Strain $\mathrm{GB} \Omega V$ does not express soxVW and is unable to grow lithoautotrophically with thiosulfate, whereas heterotrophic growth is unaffected. Complementation of strain GB $\Omega V$ with soxVW in trans by plasmid pBHP6 resulted in the wildtype phenotype (Bardischewsky \& Friedrich, 2001b). To analyse if both gene products were required for chemotrophic growth with thiosulfate, strain $\mathrm{GB} \Omega \mathrm{V}$ was complemented either with soxV located on plasmid pRIPV phoA or with soxW located on plasmid pRIN2.6. The amount of SoxW in cells of strain GB $\Omega V$ harbouring soxW in trans was about $50 \%$ as compared to the wild-type as verified by immunoblot analysis (data not shown). The resulting transconjugant $\mathrm{GB} \Omega \mathrm{V}$ (pRIPVphoA), expressing only soxV, was able to grow lithoautotrophically with thiosulfate, whereas strain $\mathrm{GB} \Omega \mathrm{V}$ (pRIN2.6), expressing only soxW, was not (data not shown). Therefore, exclusively SoxV but not SoxW was required for autotrophic growth with thiosulfate in $P$. pantotrophus. This result suggested that SoxW was not the exclusive partner for electron transfer of SoxV. These results were in accordance with those obtained for Rhodovulum sulfidophilum (Appia-Ayme \& Berks, 2002).

\section{The redox state of SoxW}

The direction in which SoxV transferred electrons was examined from the redox state of SoxW in vivo. The redox state of proteins of whole cells was trapped upon their precipitation with trichloroacetic acid, and free thiol groups were then alkylated with AMS as described in Methods. Alkylation of SoxW with AMS causes an increase of the molecular mass, resulting in a slightly decreased mobility in non-reducing SDS-PAGE. Immunoblotting of AMS-treated proteins isolated from the wild-type revealed a slightly decreased mobility of SoxW, demonstrating that SoxW was present in the reduced state in the wild-type. Immunoblotting of AMS-treated proteins of strain GB $\Omega \mathrm{V}$ (pRIN2.6), which expressed soxW but not $\operatorname{sox} V$, demonstrated that SoxW was present in the oxidized state in this strain (Fig. 1). No SoxW antigens were detected from strains GB $\Omega V$ and $\mathrm{GB} \Omega \mathrm{V}$ (pRIPVphoA), confirming previous results (data not shown). From these data it was concluded that SoxW of $P$. pantotrophus was involved in a reduction reaction and that SoxV was required to maintain SoxW in the reduced state. A similar conclusion was drawn for the SoxVW system of the anaerobic phototrophic sulfur-oxidizing bacterium Rhodovulum sulfidophilum (Appia-Ayme \& Berks, 2002).

\section{Chemical complementation of strain $\mathrm{GB} \Omega \mathrm{V}$}

The phenotypes of some $d s b A B$ - and $c c d A / d s b D$-defective strains could be restored by addition of thiol compounds to the medium (Bardwell et al., 1993; Sambongi \& Ferguson, 1994, 1996). Since the direction of the electron transfer from the cytoplasm to the periplasm appeared to be identical with that of the DsbD system of E. coli (Rietsch et al., 1997; Stewart et al., 1999; Chung et al., 2000; Katzen \& Beckwith, 2000) the effect of reductants on the thiosulfateoxidizing activity of whole cells of the mutant strain was examined. Indeed, addition of reductant ( $1 \mathrm{mM}$ DTT) to mixotrophically cultivated strain $\mathrm{GB} \Omega V$ in the early stationary phase resulted in a 50-fold increase in formation of the thiosulfate-oxidizing activity of whole cells (Fig. 2) while addition of DTT had no effect on the thiosulfate-oxidizing activity of whole cells of the wild-type (data not shown).

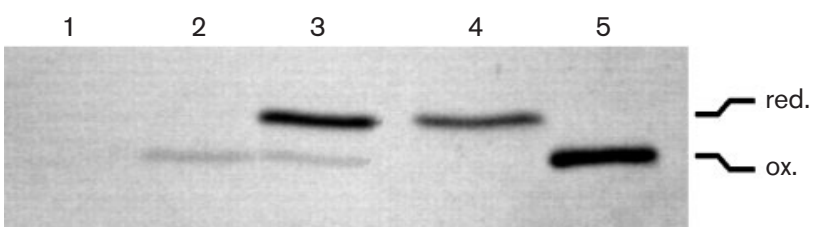

Fig. 1. Electrophoretic separation of oxidized and reduced SoxW after modification with AMS. Cell extracts were subjected to immunoblot analysis after SDS-PAGE under nonreducing conditions. $\mathrm{GB} \Omega \mathrm{V}$ (lane 1), $\mathrm{GB} \Omega \mathrm{V}(\mathrm{pRIN2.6)}$ (lane 2) and GB17 (lane 3) were cultivated mixotrophically with thiosulfate. As a control, $10 \mu \mathrm{g}$ TCEP-reduced (lane 4) and airoxidized (lane 5) periplasmic proteins were treated with AMS. 


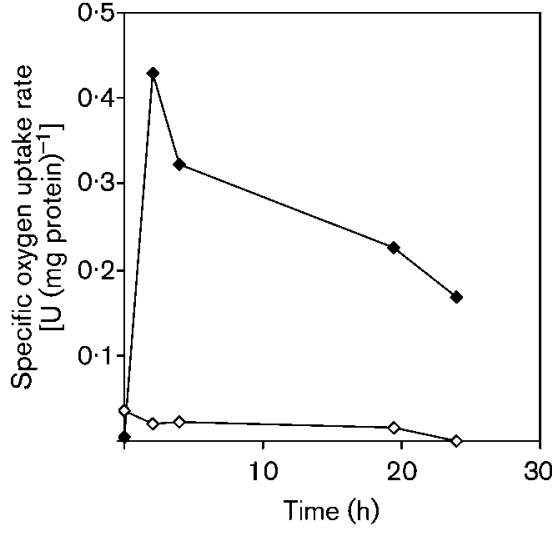

Fig. 2. Specific thiosulfate-dependent oxygen uptake rate of whole cells of the mutant strain $\mathrm{GB} \Omega \mathrm{V}$ cultivated mixotrophically in the presence $(\diamond)$ and absence $(\diamond)$ of $1 \mathrm{mM}$ DTT.

This result differed from that reported for a SoxVW-deficient mutant of the anaerobic phototrophic thiosulfate-oxidizing bacterium Rhodovulum sulfidophilum (Appia-Ayme \& Berks, 2002). A chemical complementation of cell extracts with DTT was not possible since low-molecular-mass thiols interfere with the assay system by chemically reducing horse cytochrome $c$.

\section{Thiosulfate oxidation in strain $\mathrm{GB} \Omega \mathrm{V}$}

Expression of the sox genes and stability of the respective structural Sox proteins was not affected in mutant $G B \Omega V$. Since CcdA homologues are involved in the maturation of $c$-type cytochromes it was proposed for Rhodovulum sulfidophilum that SoxV could be involved in the maturation of one of the Sox proteins (Appia-Ayme \& Berks, 2002). To uncover the specific function of SoxVW, oxidation of thiosulfate by the wild-type and strain GB $\Omega$ V was examined in vivo and in vitro. Cells were cultivated mixotrophically with succinate plus thiosulfate as strain GB $\Omega V$ is unable to grow lithoautotrophically with thiosulfate (Bardischewsky \& Friedrich, 2001b). Wild-type cells exhibited a high thiosulfate-dependent oxygen uptake rate after the culture entered the stationary phase, whereas from cells of strain

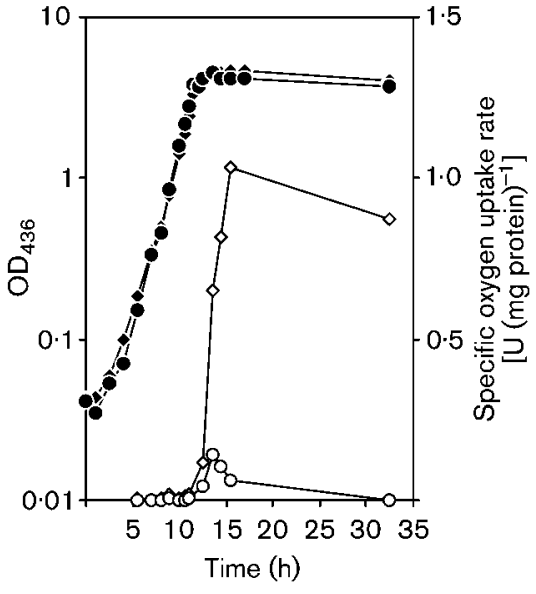

Fig. 3. Specific thiosulfate-dependent oxygen uptake rate of $P$. pantotrophus strains $\mathrm{GB} 17$ and $\mathrm{GB} \Omega \mathrm{V}$ during mixotrophic growth. Wild-type GB17 $(\diamond, \diamond)$ and mutant strain $\mathrm{GB} \Omega \mathrm{V}(\bullet$, $\bigcirc)$ were cultivated mixotrophically with succinate plus thiosulfate. Cell growth was monitored by measuring the $\mathrm{OD}_{436}$ (filled symbols). The thiosulfate-dependent oxygen uptake rate of whole cells was determined with an oxygen electrode (open symbols).

$\mathrm{GB} \Omega$ V only a minor activity of about $14 \%$ of that determined from the wild-type was transiently determined, which, however, was distinct (Fig. 3). These differences in thiosulfateoxidizing activities of whole cells prompted us to examine the activities of cell extracts. Surprisingly, the thiosulfatedependent cytochrome $c$ reduction rate of the periplasmic fraction from cells of strain $\mathrm{GB} \Omega \mathrm{V}$ was almost identical to that observed from the wild-type while the thiosulfatedependent cytochrome $c$ reduction rate of the A65 fraction of strain $G B \Omega V$ was about half of that of the wild-type. Furthermore, the thiosulfate-dependent electron yields of A65 extracts from $\mathrm{GB} \Omega \mathrm{V}$ and the wild-type were almost identical and amounted to $81-86 \%$ of the theoretical yield (Table 1). Thus, the proteins of the sulfur-oxidizing system were fully functional in extracts from the mutant strain $\mathrm{GB} \Omega \mathrm{V}$. Therefore, the low thiosulfate-oxidation rate of whole cells of the mutant strain is not due to a defect in maturation of one of the Sox proteins.

Table 1. Specific activity of whole cells and A65 extracts from $P$. pantotrophus GB17 and $\mathrm{GB} \Omega \mathrm{V}$

\begin{tabular}{|lcccc|}
\hline \multirow{3}{*}{ Strain } & \multicolumn{3}{c}{ Specific activity $(\mathbf{m U})$} & \multirow{2}{*}{ Yield of electrons A65 } \\
\cline { 2 - 4 } & Whole cells $^{\star}$ & Periplasmic fraction $\dagger$ & A65 extract $\dagger$ & \\
\hline GB17 & $520 \cdot 0$ & $5 \cdot 0$ & $1 \cdot 3$ & $6 \cdot 5$ \\
GB $\Omega V$ & $10 \cdot 0$ & $5 \cdot 1$ & $0 \cdot 6$ & $6 \cdot 9$ \\
\hline
\end{tabular}

${ }^{\star}$ Thiosulfate-dependent $\mathrm{O}_{2}$ uptake rate $\left[\mu \mathrm{mol} \mathrm{O} \mathrm{O}_{2} \min ^{-1}(\mathrm{mg} \text { protein })^{-1}\right]$.

$\dagger$ Cytochrome $c$ reduction rate $(\mathrm{mU})$.

$\ddagger$ Mol cytochrome $c$ reduced (mol thiosulfate) ${ }^{-1}$. 
The similar specific activities of thiosulfate-dependent oxygen uptake of cell fractions of strains GB17 and GB $\Omega$ V suggested that SoxV affected either the electron transfer from the Sox system to the cytoplasmic membrane or a vital reaction required for maintaining the Sox system in a functional state. To discriminate between these two possibilities, the thiosulfate-oxidizing activity was examined with molecular oxygen as the terminal electron acceptor, using isolated membranes which were combined with the A65 fraction either from wild-type cells or from strain GB $\Omega V$. The similar specific thiosulfate-dependent oxygen uptake rate using the membrane fractions of both strains when mixed with the A65 fraction of the wild-type demonstrated that the electron transport via the respiratory chain was fully functional in strain $G B \Omega V$. The $A 65$ fraction of strain $G B \Omega V$ supplemented with the membrane fraction isolated from strain $\mathrm{GB} \Omega \mathrm{V}$ resulted in an activity of $13.7 \mathrm{mU}$ as compared to $22.7 \mathrm{mU}$ using the A65 fraction of the wild-type (Table 2). This result was in accordance with the decreased thiosulfate-dependent cytochrome $c$ reduction rate by the A65 fraction isolated from strain GB $\Omega$ V (Table 1). Moreover, the result suggested SoxVW to be involved in the reaction cycle of the Sox enzyme system in vivo.

\section{Complementation of the $\operatorname{ccd} A$-negative strain TP43 with soxV}

Strain TP43 is defective in expression of $c c d A$ and therefore unable to synthesize mature $c$-type cytochromes (Bardischewsky \& Friedrich, 2001a). In view of the high identity in primary structure of CcdA and SoxV, strain TP43 was complemented with pBHP6 and pRIPVphoA to verify if SoxV was able to substitute for CcdA. Strains TP43(pBHP6) and TP43(pRIPVphoA) were analysed for their TMPD-oxidizing ability, diagnostic for cytochrome $c$ oxidase. Furthermore, cell extracts from both strains were analysed for the $c$-type cytochrome SoxXA by immunoblot analysis. Surprisingly, despite the high structural homology of CcdA and SoxV of P. pantotrophus the wild-type

Table 2. Thiosulfate-dependent activities of membranes and A65 extracts from $P$. pantotrophus GB17 and GB $\Omega$ V

\begin{tabular}{|lcc|}
\hline Membranes & A65 extract & Activity $^{*}$ \\
\hline GB17 & GB17 & $23 \cdot 2$ \\
GB $\Omega$ V & $\mathrm{GB} \Omega V$ & $13 \cdot 7$ \\
GB17 & $\mathrm{GB} \Omega \mathrm{V}$ & $11 \cdot 0$ \\
GB $\Omega$ V & $\mathrm{GB} 17$ & $22 \cdot 7$ \\
GB17 & - & 0 \\
GB $\Omega$ V & - & 0 \\
- & $\mathrm{GB} 17$ & 0 \\
- & $\mathrm{GB} \Omega \mathrm{V}$ & 0 \\
\hline
\end{tabular}

*Thiosulfate-dependent $\mathrm{O}_{2}$ uptake rate $\left[\begin{array}{llll}\mu \mathrm{mol} & \mathrm{O}_{2} & \mathrm{~min}^{-1} & (\mathrm{mg}\end{array}\right.$ protein $)^{-1}$ ]. phenotype was not restored in strain TP43 by in trans expression of $\operatorname{sox} V$ (data not shown).

\section{DISCUSSION}

In this study we have confirmed that the CcdA-like membrane protein SoxV is essential for aerobic chemotrophic sulfur oxidation of $P$. pantotrophus. We have further demonstrated that SoxV reduces the periplasmic thioredoxin SoxW, and addition of the reductant DTT to the medium resulted in a partial restoration of the thiosulfateoxidizing activity of whole cells of strain GBQV. The effect of DTT supports the finding that SoxVW are involved in a reducing step necessary for full activity of the thiosulfateoxidizing system. We have demonstrated that SoxV but not SoxW is essential for lithoautotrophic growth of $P$. pantotrophus with thiosulfate. Therefore SoxV is not restricted to SoxW and appears to accept more than one reaction partner. Although Rhodovulum sulfidophilum is an anaerobic phototroph, the results and conclusions previously reported for this bacterium were identical to those obtained here for $P$. pantotrophus except for the effect of low-molecular-mass thiols, which did not restore thiosulfate-oxidizing activity in a soxV mutant of Rhodovulum sulfidophilum (Appia-Ayme \& Berks, 2002). Although the general function of SoxV is evident from its essentiality for thiosulfate oxidation in vivo, its specific function within the Sox enzyme system is not fully resolved. Proteins of the CcdA and DsbD family were shown to be involved in maturation of $c$-type cytochromes by maintaining the conserved cysteines of the apocytochrome reduced prior to haem attachment. We have previously shown that neither the biosynthesis of $c$-type cytochromes nor the expression of the sox structural genes or the stability of the proteins of the Sox system are affected in strain GB $\Omega$ V (Bardischewsky \& Friedrich, 2001b).

Analysis of the activity of whole cells and cell extracts of the wild-type and of the mutant strain $G B \Omega V$ allowed a deeper insight into the function of SoxV during thiosulfate

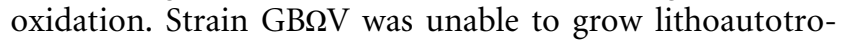
phically with thiosulfate. After mixotrophic cultivation, whole cells of the mutant strain displayed at most $14 \%$ of the thiosulfate-dependent oxygen uptake rate as compared to the wild-type. In contrast, when analysing cell-free extracts from both strains only insignificant differences in activities and yields of electrons were observed. Therefore SoxYZ, SoxXA, SoxB and SoxCD appeared to be identically functional in strain $\mathrm{GB} \Omega \mathrm{V}$ as in the wild-type, and the mutation in soxVW did not cause a defect in protein maturation or biosynthesis as in the case of DsbD and CcdA.

The mutation in soxV exclusively affected thiosulfate oxidation of strain $\mathrm{GB} \Omega \mathrm{V}$ in vivo but not in vitro, suggesting that SoxV might be involved in the transport of electrons from the Sox system to the cytoplasmic membrane in $P$. pantotrophus. However, the thiosulfate-dependent oxygenuptake rate of mixtures of cell-free extracts and membrane 


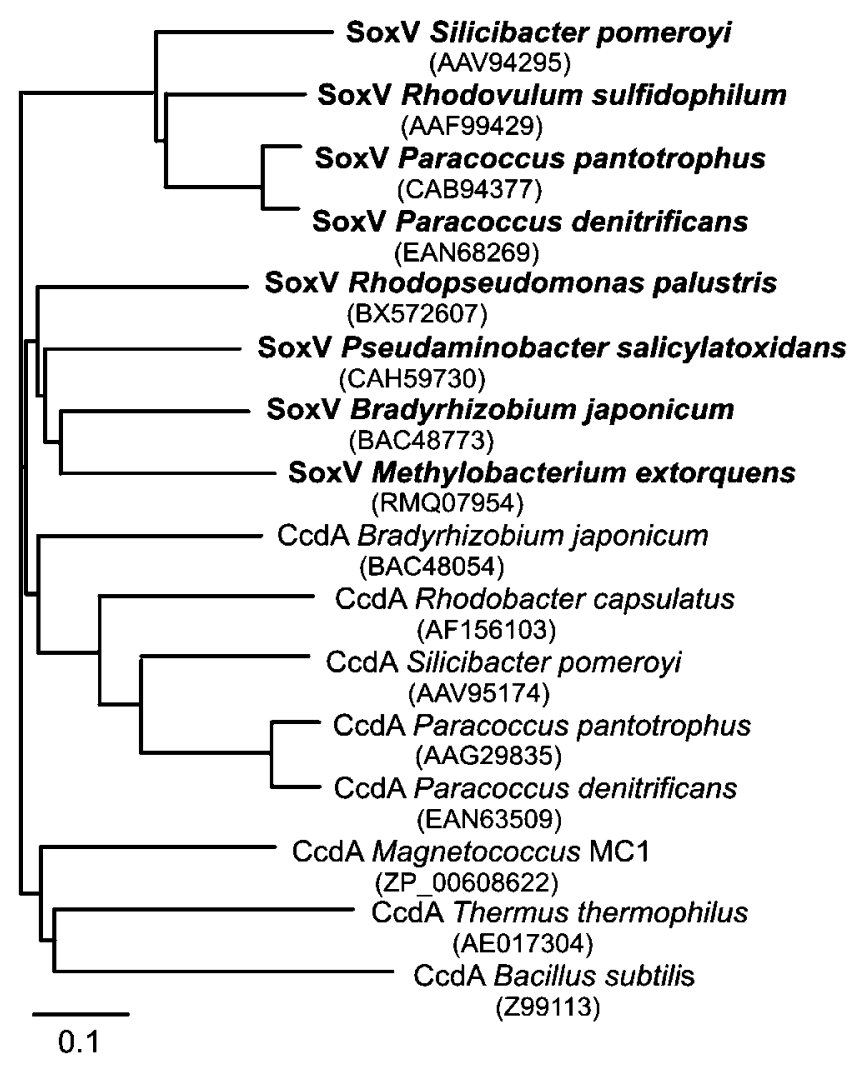

Fig. 4. Phylogenetic relationship of SoxV of $P$. pantotrophus to homologous proteins of other bacteria. The accession numbers of the proteins are given in parentheses.

fractions from GB$\Omega V$ and the wild-type were similar, demonstrating that SoxV was not involved in the transport of electrons from the Sox system to the cytoplasmic membrane.

Thioredoxins are not only involved in maturation of proteins but they are also essential for the catalytic activity of several enzymes such as phosphoadenosine-phosphosulfate reductase and arsenate reductase (Lillig et al., 1999; Shi et al., 1999). An important recycling function of thioredoxins during catalysis has been described for a methionine sulfoxide reductase. This enzyme was shown to bind its substrate methionine sulfoxide via the thiol group of a highly conserved cysteine residue. After the release of methionine the active-site cysteine has to be re-reduced by a thioredoxin-regenerating system or DTT (Boschi-Muller et al., 2000; Lowther et al., 2000).

The overall thiosulfate-oxidizing activity of cell-free extracts from mutant strain $G B \Omega$ V and the wild-type was only about $1 \%$ as compared with the oxygen uptake rate of whole cells of the wild-type (Table 1). This low thiosulfate oxidation in vitro as compared to that in vivo might indicate that SoxVW are involved in the catalytic cycle, e.g. by a recurrent reduction of cysteine residues of one of the Sox proteins.

Despite the marginal identity of $24 \%$ between CcdA of Rhodobacter capsulatus and the $\beta$-domain of DsbD of E. coli
Katzen et al. (2002) demonstrated that these two proteins were functional homologues. The expression of $c c d A$ from Rhodobacter capsulatus in an E. coli $d s b D$-null strain restored the wild-type phenotype as well as a $c c d A$-defective mutant of Rhodobacter capsulatus was complemented by the expression of the E. coli $d s b D$ gene in trans. The amino acid sequence of CcdA and SoxV of P. pantotrophus is $42 \cdot 3 \%$ identical and the two proteins have a similar predicted secondary structure (Bardischewsky \& Friedrich. 2001b). The thioredoxin SoxW was demonstrated to be dispensable for thiosulfate oxidation in $P$. pantotrophus, and therefore SoxV appears not to be specific for a single reaction partner. However, constitutive expression of $\operatorname{soxV}$ in the mutant strain TP43 did not restore the wild-type phenotype. This functional specificity of SoxV and CcdA is also evident from the phylogenetic distance of the proteins (Fig. 4).

Genome analysis revealed that of 18 strains harbouring the sox gene cluster, 9 contained the soxVW genes and also a typical $c c d A$ gene probably encoding the cytochrome $c$ maturation protein $\mathrm{Ccd} A$, strengthening the results that demonstrate the inability of SoxV to substitute for CcdA. Furthermore, the soxVW genes are exclusively present in strains harbouring the sox $C D$ genes, which encode sulfur dehydrogenase (Friedrich et al., 2005). This correlation may point to a functional link of the respective gene products.

\section{ACKNOWLEDGEMENTS}

This study was supported by grant Fr 318/9-1 of the Deutsche Forschungsgemeinschaft.

\section{REFERENCES}

Akyama, Y. \& Ito, K. (1993). Folding and assembly of bacterial alkaline phosphatase in vitro and in vivo. J Biol Chem 268, 81468150.

Altenbuchner, J., Viell, P. \& Pelletier, I. (1992). Positive selection vector based on palindromic DNA sequences. Methods Enzymol 216, 457-566.

Appia-Ayme, C. \& Berks, B. C. (2002). SoxV, an orthologue of the CcdA disulfide transporter, is involved in thiosulfate oxidation in Rhodovulum sulfidophilum and reduces the periplasmic thioredoxin SoxW. Biochem Biophys Res Commun 296, 737-741.

Bardischewsky, F. \& Friedrich, C. G. (2001a). Identification of $c c d A$ in Paracoccus pantotrophus GB17: disruption of $c c d A$ causes complete deficiency in $c$-type cytochromes. J Bacteriol 183, 257-263.

Bardischewsky, F. \& Friedrich, C. G. (2001b). The sh $x V W$ locus is essential for oxidation of inorganic sulfur and molecular hydrogen by Paracoccus pantotrophus GB17: a novel function for lithotrophy. FEMS Microbiol Lett 202, 215-220.

Bardischewsky, F., Quentmeier, A., Hellwig, P., Kostka, S. \& Friedrich, C. G. (2005). Sulfur dehydrogenase of Paracoccus pantotrophus: the heme-2 domain of the molybdoprotein cytochrome $c$ complex is dispensable for catalytic activity. Biochemistry 44, 7024-7034.

Bardwell, J. C., Lee, J.-O., Jander, G., Martin, N., Belin, D. \& Beckwith, J. (1993). A pathway for disulfide bond formation in vivo. Proc Natl Acad Sci U S A 90, 1038-1042. 
Birnboim, H. C. \& Doly, J. (1979). A rapid alkaline extraction procedure for screening recombinant plasmid DNA. Nucleic Acids Res 7, 1513-1523.

Boschi-Muller, S., Azza, S., Sanglier-Cianferani, S., Talfournier, F., van Dorsselear, A. \& Branlant, G. (2000). A sulfenic acid enzyme intermediate is involved in the catalytic mechanism of peptide methionine sulfoxide reductase from Escherichia coli. J Biol Chem 275, 35908-35913.

Bowien, B., Mayer, F., Codd, G. A. \& Schlegel, H. G. (1976). Purification, some properties, and quarternary structure of the Dribulose 1,5-diphosphate carboxylase of Alcaligenes eutrophus. Arch Microbiol 110, 157-167.

Bradford, M. M. (1976). A rapid and sensitive method for the quantitation of microgram quantities of protein utilizing the principle of protein-dye binding. Anal Biochem 72, 248-254.

Bullock, W. O., Fernandez, J. M. \& Short, J. M. (1987). XL1-Blue: a high efficiency plasmid transforming recA Escherichia coli strains with beta-galactosidase selection. BioTechniques 5, 376-378.

Chandra, T. S. \& Friedrich, C. G. (1986). Tn5-induced mutations affecting sulfur-oxidizing ability (Sox) of Thiosphaera pantotropha. $J$ Bacteriol 166, 446-452.

Chung, J., Chen, T. \& Missiakas, D. (2000). Transfer of electrons across the cytoplasmic membrane by DsbD, a membrane protein involved in thiol-disulphide exchange and protein folding in the bacterial periplasm. Mol Microbiol 35, 1099-1109.

Crooke, H. \& Cole, J. (1995). The biogenesis of $c$-type cytochromes in Escherichia coli requires a membrane-bound protein, DipZ, with a protein disulphide isomerase-like domain. Mol Microbiol 15, 1139-1150.

Fabianek, R. A., Hennecke, H. \& Thöny-Meyer, L. (2000). Periplasmic protein thiol:disulfide oxidoreductases of Escherichia coli. FEMS Microbiol Rev 24, 303-316.

Felsenstein, J. (1989). PHYLIP - Phylogeny Inference Package, version 3.2. Cladistics 5, 164-166.

Friedrich, C. G., Bardischewsky, F., Rother, D., Quentmeier, A. \& Fischer, J. (2005). Prokaryotic sulfur oxidation. Curr Opin Microbiol 8, 253-259.

Gutierrez, C. \& Devedijian, J. C. (1989). A plasmid faciliating in vitro construction of phoA gene in Escherichia coli. Nucleic Acids Res 17, 3999.

Katzen, F. \& Beckwith, J. (2000). Transmembrane electron transfer by the membrane protein DsbD occurs via a disulfide bond cascade. Cell 103, 769-779.

Katzen, F., Deshmukh, M., Daldal, F. \& Beckwith, J. (2002). Evolutionary domain fusion expanded the substrate specificity of the transmembrane electron transporter DsbD. EMBO J 21, 3960-3969.

Kobayashi, T., Kishigami, S., Sone, M., Inokuchi, H., Mogi, T. \& Ito, K. (1997). Respiratory chain is required to maintain oxidized states of the DsbA-DsbB disulfide bond formation system in aerobically growing Escherichia coli cells. Proc Natl Acad Sci U S A 94, 11857-11862.

Lillig, C. H., Prior, A., Schwenn, J. D., Aslund, F., Ritz, D., VlamisGardikas, A. \& Holmgren, A. (1999). New thioredoxins and glutaredoxins as electron donors of $3^{\prime}$-phosphoadenylsulfate reductase. J Biol Chem 274, 7695-7698.

Lowther, W. T., Brot, N., Weissbach, H. \& Matthews, B. W. (2000). Structure and mechanism of peptide methionine sulfoxide reductase, an "anti-oxidation" enzyme. Biochemistry 39, 13307-13312.

Martin, J. L. (1995). Thioredoxin - a fold for all reasons. Structure 3, 245-250.

Missiakis, D. \& Raina, S. (1997). Protein folding in the bacterial periplasm. J Bacteriol 179, 2465-2471.
Okamoto, K., Baba, T., Yamanaka, H., Akashi, N. \& Fujii, Y. (1995). Disulfide bond formation and secretion of Escherichia coli heat stable enterotoxin II. J Bacteriol 177, 4579-4586.

Page, R. D. M. (1996). TREEVIEW: an application to display phylogenetic trees on personal computers. Comput Appl Biosci 12, 357-358.

Pfitzner, U., Odenwald, A., Ostermann, T., Weingard, L., Ludwig, B. \& Richter, O. M. (1998). Cytochrome $c$ oxidase (heme $a a_{3}$ ) from Paracoccus denitrificans: analysis of mutations in putative proton channels of subunit I. J Bioenerg Biomembr 30, 83-97.

Quentmeier, A., Kraft, R., Kostka, S., Klockenkämper, R. \& Friedrich, C. G. (2000). Characterization of a new type of sulfite dehydrogenase from Paracoccus pantotrophus GB17. Arch Microbiol 173, 117-125.

Rainey, F. A., Kelly, D. P., Stackebrandt, E., Burghardt, J., Hiraishi, A., Katayama, Y. \& Wood, A. P. (1999). A re-evaluation of the taxonomy of Paracoccus denitrificans and a proposal for the combination Paracoccus pantotrophus comb. nov. Int J Syst Bacteriol 49, 645-651.

Rietsch, A., Bessette, P., Georgiou, G. \& Beckwith, J. (1997). Reduction of the periplasmic disulfide bond isomerase, DsbC, occurs by passage of electrons from cytoplasmic thioredoxin. J Bacteriol 179, 6602-6608.

Ritz, D. \& Beckwith, J. (2001). Roles of thiol-redox pathways in bacteria. Annu Rev Microbiol 55, 21-48.

Robertson, L. A. \& Kuenen, J. G. (1983). Thiosphaera pantotropha gen. nov. sp. nov., a facultatively anaerobic, facultative autotrophic sulphur bacterium. J Gen Microbiol 129, 2847-2855.

Rother, D., Orawski, G., Bardischewsky, F. \& Friedrich, C. G. (2005). SoxRS-mediated regulation of chemotrophic sulfur oxidation in Paracoccus pantotrophus. Microbiology 151, 1707-1716.

Sambongi, Y. \& Ferguson, S. J. (1994). Specific thiol compounds complement deficiency in $c$-type cytochrome biogenesis in Escherichia coli carrying a mutation in a membrane-bound disulphide isomerase-like protein. FEBS Lett 353, 235-238.

Sambongi, Y. \& Ferguson, S. J. (1996). Mutants of Escherichia coli lacking disulphide oxidoreductases DsbA and DsbB cannot synthesise an exogenous monohaem $c$-type cytochrome except in the presence of disulphide compounds. FEBS Lett 398, 265-268.

Sambrook, J., Maniatis, T. \& Fritsch, E. F. (1989). Molecular Cloning: a Laboratory Manual, 2nd edn. Cold Spring Harbor, NY: Cold Spring Harbor Laboratory.

Schiött, T., von Wachenfeldt, C. \& Hederstedt, L. (1997). Identification and characterization of the $c c d A$ gene, required for cytochrome $c$ synthesis in Bacillus subtilis. J Bacteriol 179, 1962-1973.

Shi, J., Vlamis-Gardikas, A., Åslund, F., Holmgrens, A. \& Rosen, B. P. (1999). Reactivity of glutaredoxins 1, 2, and 3 from Escherichia coli shows that glutaredoxin 2 is the primary hydrogen donor to ArsC-catalyzed arsenate reduction. J Biol Chem 274, 36039-36042.

Simon, R., Priefer, U. \& Pühler, A. (1983). A broad host range mobilization system for in vivo genetic engineering: transposon mutagenesis in Gram-negative bacteria. Bio/Technology 1, 784-790.

Sørbø, B. (1957). A colorimetric method for the determination of thiosulfate. Biochim Biophys Acta 23, 412-416.

Stewart, E. J., Katzen, F. \& Beckwith, J. (1999). Six conserved cysteines of the membrane protein DsbD are required for the transfer of electrons from the cytoplasm to the periplasm of Escherichia coli. EMBO J 18, 5963-5971.

Thompson, J. D., Higgins, D. G. \& Gibson, T. J. (1994). CLUSTAL W: improving the sensitivity of progressive multiple sequence alignment through sequence weighting, position-specific gap penalties and weight matrix choice. Nucleic Acids Res 22, 4673-4680.

Thöny-Meyer, L. (1997). Biogenesis of respiratory cytochromes in bacteria. Microbiol Mol Biol Rev 61, 337-376. 
Towbin, H., Staehelin, T. \& Gordon, J. (1979). Electrophoretic transfer of proteins from polyacrylamide gels to nitrocellulose sheets: procedure and some applications. Proc Natl Acad Sci U S A 76, 4350-4354.

Wodara, C., Bardischewsky, F. \& Friedrich, C. G. (1997). Cloning and characterization of sulfite dehydrogenase, two c-type cytochromes, and a flavoprotein of Paracoccus denitrificans GB17: essential role of sulfite dehydrogenase in lithotrophic sulfur oxidation. J Bacteriol 179, 5014-5023.

Yamanaka, H., Kameyama, M., Baba, T., Fujii, Y. \& Okamoto, K. (1994). Maturation pathway of Escherichia coli heat stable enterotoxin I: requirement of DsbA for disulphide bond formation. J Bacteriol 176, 2906-2913. 